\title{
Aspectos da dimensão ambiental e a educação química: discutindo possibilidades
}

Claudia Christina Bravo e Sá Carneiro ccbcarneiro@hotmail.com 0000-0001-6536-126X Universidade Federal do Ceará

Francisco Marcôncio Targino de Moura

marconcio@gmail.com

0000-0002-0800-9347.

Universidade Federal do Ceará

\section{RESUMO}

A educação ambiental e a contextualização do ensino têm tido recorrente abordagem em trabalhos científicos de várias áreas do conhecimento na atualidade. Em encontros, conferências e debates o tema tem lugar relevante, sendo ponto comum a busca por uma nova mentalidade social, ética e moral no que diz respeito a questões ambientais. Nesse sentido, a educação científica, mais especificamente a educação química tem papel decisivo, devendo ser capaz não só de sensibilizar, mas de fortalecer a consciência de alunos e futuros profissionais cidadãos. No entanto, vêm as questões: os currículos de formação docente, no caso, as Licenciaturas, expressam essa preocupação? Essa questão está sendo abordada pelos professores e por outros agentes educacionais? E o que dizer sobre a formação dos formadores que vão formar os futuros professores da Educação Básica? Neste artigo vamos nos debruçar sobre essas questões, que englobam as determinações legais, as situações reais, as necessidades formativas e as perspectivas para uma formação cidadã. Trata-se, na verdade, de algumas reflexões baseadas em trabalhos que englobam o assunto, numa perspectiva de acirrar o debate sobre o tema, de discutir um assunto que se encontra em pauta e vem sendo discutido com frequência.

PALAVRAS-CHAVE: Dimensão ambiental. Educação química. Legislação e formação cidadã. 


\section{INTRODUÇÃO}

A educação ambiental e a contextualização do ensino têm tido recorrente abordagem em trabalhos científicos de várias áreas do conhecimento na atualidade. Em encontros, conferências e debates o tema tem lugar relevante, sendo ponto comum a busca por uma nova mentalidade social, ética e moral no que diz respeito a questões ambientais.

Com a legitimação da questão ambiental inserida nas pesquisas em educação científica, decorrente das discussões sobre a neutralidade da ciência no final dos anos 70, os educadores em Ciências voltaram o enfoque de suas pesquisas aos porquês e como do processo ensino e aprendizagem, versando sobre as situações conceituais, sociais e de aplicação, impacto industrial e tecnológico, os processos da Ciência, em particular, da Química.

Quanto a esse assunto, Cachapuz (2012) aponta que existe um estreito laço entre o exercício da cidadania participativa e o progresso do conhecimento científico. Para o autor, a Ciência e a Tecnologia necessitam de duas condições primordiais para a formação de sociedades democráticas: liberdade e pensamento crítico. Daí, a importância do ensino de Ciências, mais especificamente do ensino de Química.

Nas nossas vidas, cotidianamente, surgem problemas às vezes bem complexos e que exigem decisões. Podemos citar problemas ambientais, éticos, questões de sustentabilidade, de transportes, de poluição etc. Diante disso, uma cultura científica se torna uma ferramenta necessária para a participação das decisões, para que possamos compreender minimamente os processos para suas soluções.

Se o problema se diz político e, como sabemos, demanda mais tempo, não nos cabe aguardar passivamente, esperando das camadas políticas qualquer iniciativa. Um ato de cidadania será torná-los claros, transparentes, através de programas de Ciência e Tecnologia voltados às necessidades humanas básicas. Acreditamos que o papel da Academia também deve ser esse.

Como é de conhecimento, nos anos 70, o Movimento Ciência, Tecnologia e Sociedade (CTS) emergiu, pondo em cheque a questão da ciência neutra e, os problemas ambientais, se colocando como primordiais para o desenvolvimento humano. No entanto, nos anos 90 essa tríade se tornou fundamental para uma compreensão do mundo em que vivemos. A Ciência e a Tecnologia estão sob a égide de uma sociedade onde se destacam as consequências de seu desenvolvimento, trazendo à tona as dimensões humanas, sociais, culturais e cidadania.

Informações e conhecimento são basilares para que analisemos questões conflituosas, que incluem interpretações controversas, tomadas de decisões, que dependem de valores sociais e pessoais. Não podemos negar que a Ciência e a Tecnologia têm crescido amplamente, mas, também, esse crescimento tem trazido situações não tão alvissareiras, como o agravamento da miséria, a degradação ambiental, os conflitos sociais, políticos, éticos, étnicos etc. Assim, é necessário que tenhamos cidadãos aptos a utilizar seus conhecimentos de modo a fundamentar suas posições e ações. 
Nesse sentido, a educação científica, mais especificamente a educação química tem papel decisivo, devendo ser capaz não só de sensibilizar, mas de fortalecer a consciência de alunos e futuros profissionais cidadãos.

No entanto, vêm as questões: os currículos de formação docente, no caso as Licenciaturas, expressam essa preocupação? Essa questão está sendo abordada pelos professores e por outros agentes educacionais? E o que dizer sobre a formação dos formadores que vão formar os futuros professores da Educação Básica?

Neste artigo vamos nos debruçar sobre essas questões, que englobam as determinações legais, as situações reais, as necessidades formativas e as perspectivas para uma formação cidadã.

Trata-se, na verdade, de algumas reflexões baseadas em trabalhos que englobam o assunto, numa perspectiva de acirrar o debate sobre o tema, de discutir um assunto que se encontra em pauta e vem sendo discutido com frequência.

\section{O QUE DIZ A LEGISLAÇÃO}

Nos últimos anos, temos assistido a uma série de reformas, tanto na Educação Básica, quanto no Ensino Superior. No entanto, se nos debruçarmos sobre a formação de professores de Química, percebemos que essa formação, já passados mais de vinte anos da promulgação de LDB, não sofreu as mudanças necessárias, principalmente as relacionadas a situações como a articulação entre as disciplinas pedagógicas e específicas; dicotomia entre Licenciatura e Bacharelado e distanciamento entre a escola de Educação Básica e a Universidade como centro de formação (PEREIRA, 1998; GATTI, 2000, MALDANER, 2000; SCHNETZLER, 2000).

Também, um fato que se coloca e não pode ser esquecido, ou seja, um aspecto primordial na formação dos professores que irão atuar na Educação Básica é fazêlos cumprir o seu objetivo central, que é a consolidação da formação de jovens para o exercício consciente da cidadania (BRASIL, 1998). Mas, a legislação, que rege todas as reformas, parece não estar sendo contemplada também nesse quesito.

A Lei de Diretrizes e Bases da Educação Nacional, LDB 9394/96 foi bem significativa em relação à importância da questão ambiental ao considerar a compreensão do ambiente natural como ponto fundamental para a Educação Básica. Os Parâmetros Curriculares Nacionais Ensino Médio - PCNEM (BRASIL, 2000) e as Orientações Curriculares para o Ensino Médio para Ciências da Natureza, Matemática e suas Tecnologias (BRASIL, 2006) enfatizam que a contextualização socio-histórica é um fator importante para que ocorra um ensino de Química preocupado com a formação cidadã. Tais documentos defendem, ainda, a abordagem de temas sociais do cotidiano do aluno entrosados com a teoria, não devendo ser utilizados como simples elementos ilustrativos ou motivacionais (BRASIL, 2006).

Em relação aos Cursos de Química (Bacharelado e Licenciatu-ra), as Diretrizes Curriculares Nacionais, decorrentes da LDB e do Edital 04/97 da Secretaria da Educação Superior do MEC, determinam que, além da formação didática, científica e tecnológica sólida do profissional, deve ser garantida uma formação humanística que possibilite ao egresso exercer sua profissão em defesa da vida, do ambiente e 
do bem-estar dos cidadãos. Por outro lado, o profissional em Química deverá ser capaz, ainda, de avaliar de modo crítico a aplicação do conhecimento em Química, considerando o diagnóstico e o equacionamento de questões sociais e ambientais. As Diretrizes Curriculares Nacionais para os Cursos de Química segundo o parecer CNE/CES de 06 de novembro de 2001 reiteram esse fato.

Ainda em relação às questões legais a respeito da questão ambiental, a Lei no 9795, de abril de 1999, institui a Política Nacional de Educação Ambiental no Brasil, destacando no Art. 5o os objetivos da Educação Ambiental, entre eles, a reflexão sobre Ciência e Tecnologia, isto é, envolve explicitar sua complexidade e mostrar seu relacionamento com a C\&T.

Portanto, como se pode constatar, em termos legais, a dimensão ambiental e cidadã se encontram contempladas. Mas, como o tema se desenvolve e sua abordagem, é a questão.

\section{EDUCAÇÃO QUÍMICA, EDUCAÇÃO AMBIENTAL E EDUCAR PARA A CIDADANIA}

Educação, currículo e ensino são reflexos de um projeto de sociedade, um projeto constituído historicamente, com bases epistemológicas, que determinam a própria natureza da Ciência. A neutralidade científica, predominante nas décadas de 50 e 60, que se relacionava ao caráter utilitarista da Ciência, deu lugar à preocupação ambiental, à reflexão sobre a Ciência e sua relação com a sociedade. Nas décadas de 80 e 90 as propostas para a educação científica abordavam temas sociais e científicos, na busca de formar cidadãos. Uma demanda que passou a fortalecer o chamado Movimento Ciência Tecnologia e Sociedade - CTS.

Tanto as demandas sociais, como as determinações legais estimularam a inserção da dimensão ambiental no meio educacional. Palavras como sustentabilidade, preservação, diversidade etc. passaram a fazer parte do ideário da educação brasileira. A produção acadêmica também se debruçou sobre o assunto, abordado em disciplinas, em teses e dissertações. No entanto, a valorização das dimensões políticas, relacionadas ao tema, pouco foram trabalhadas.

A ideia de criar uma educação voltada ao meio ambiente pode ser compreendida como um modo de assumir mudanças pedagógicas, de dirimir aspectos neutros em relação aos problemas políticos, sociais, culturais, econômicos e ecológicos. Trata-se, portanto, de um movimento epistemológico.

Mas o que observamos, nisso a literatura é pródiga em denunciar (Amaral, 2001; Ribeiro e Cavassan, 2012; Maknamara, 2009; Reigota, 2010), é que o ambiente não é compreendido em sua forma global, como um meio social, político, ideológico, biótico e físico, mas se restringe ao naturalismo e ao conservacionismo, colocando a natureza como recurso para o ser humano, centrando-se em conhecimentos ecológicos.

O ser cidadão engloba certos valores que devem ser interiorizados, como éticos, morais, conhecimentos científicos e tecnológicos, inerentes ao sujeito, de forma a torná-lo dono de seu conhecimento, de sua voz.

Nesse sentido, nos apoiamos em Gobara et al (1992), quando define a cidadania, de modo a capacitá-lo a analisar a relação ciência, tecnologia e 
sociedade, dando possibilidade a esse indivíduo de adquirir, produzir conhecimentos e formar opinião, visando a auxiliá-lo na discussão de temas de relevância na sociedade. Tudo isso em prol de uma melhoria na qualidade de vida em um ambiente saudável em sua totalidade, respeitando o meio cultural e o ambiente utilizado sem destruí-lo.

Um fato deve ficar claro: educar para a cidadania não se resume a propor novas teorias ou modos diferentes de ensinar, é necessário que nós, como educadores retomemos nossas próprias práticas com atitude reflexiva. É preciso que essa reflexão se insira em um pensamento voltado para a formação do sujeito que constrói sua subjetividade e se emancipe.

Com o avanço científico e tecnológico, tem sido construída uma forte dependência em relação à Química, que engloba desde a utilização de produtos até sua influência no desenvolvimento da sociedade, nos problemas cotidianos relativos ao ambiente, seus efeitos e busca de soluções. É preciso, portanto, para o exercício da cidadania, que o cidadão saiba fazer um julgamento crítico e político, precisa não só ter a compreensão da Química, mas, também, da sociedade em que está inserido.

O ensino, nessas circunstâncias, não pode se restringir somente à questão contextual, a uma discussão puramente ideológica, nem tão pouco ao estudo de conceitos químicos isolados e descontextualizados. Tais dimensões devem ser contempladas em um todo simbiótico. Portanto, a educação química deve ser trabalhada dentro de uma concepção de Ciência que tem no seu âmago o seu papel social, em um contexto social e histórico, lembrando que a compreensão da ciência química é uma atividade humana, proveniente de uma construção social.

\section{ABORDAGEM CONTEXTUALIZADA DO ENSINO E APRENDIZAGEM}

Considerando que a contextualização do ensino e a Educação Ambiental têm sido constantemente abordadas em trabalhos científicos em diversas áreas, percebeu-se que a legislação brasileira tem se voltado para um ensino contextualizado com ênfase no cotidiano. Por sinal, há autores que defendem haver uma contextualização permanente nos currículos escolares.

Torna-se importante enfatizar, que a abordagem contextualizada do ensino tem sido discutida e criticada por pesquisadores da área de ensino de Ciências devido suas intencionalidades se direcionarem, principalmente, à preparação exclusiva para a inserção no mundo produtivo. Acerca disso, Lopes (2002) ao se referir ao conceito de recontextualização com o objetivo de desproblematizar os PCNs para o Ensino Médio, acredita que a contextualização é um conceito central dos PCNEM e destaca que a "educação para a vida" - expressão bastante utilizada nesse documento - finda se restringindo a uma "dimensão especialmente produtiva do ponto de vista econômico, em detrimento de sua dimensão cultural mais ampla" (LOPES, 2002, p. 390).

No caso específico da Química, sua presença no cotidiano das pessoas é um fato, o que justifica o indivíduo aprender Química. No entanto, alguns pontos abordados em pesquisas na área, de uns tempos para cá, merecem destaque no que se refere à educação química nas escolas: Santos e Schnetzler (2010) apontam que, segundo estudos, há demonstração de que o ensino atual de Química não serve para o cidadão, não tem a menor utilidade. A nosso ver, uma situação que 
pouco mudou nos últimos anos. Santos et al (2007), por seu lado, acreditam que o professor não consegue mudar suas aulas, presos a conteúdos curriculares tradicionais. Segundo Maldaner (2000), a prática corrente dos professores de Química em nossas escolas não é a de tratar as inter-relações que se estabelecem entre esses conteúdos e, muito menos, com questões mais amplas da sociedade. Já Machado e Mortimer (2007) assumem que uma aula de Química é um espaço de construção do pensamento químico e de reelaborações de visões de mundo.

Educar para a cidadania considera o que denominamos uma demanda ambiental no ensino de Ciências-Química, o que implica em compreender o contexto, em termos uma educação moral, fundamentada em valores éticos que darão um norte ao comportamento dos alunos e lhes permita desenvolver a aptidão de discutir criticamente, de discernir, de tomar decisões acerca de problemas voltados à coletividade.

Cidadania refere-se à participação do indivíduo na sociedade, mas esse indivíduo precisa de informações vinculadas aos problemas que afetam na sociedade, o que exige um posicionamento, uma tomada de decisão. O conhecimento químico enquadra-se nessas condições.

Questões como a utilização de produtos químicos, impactos desenvolvimentistas, qualidade de vida, efeitos ambientais das aplicações tecnológicas são pontos que devem ser discutidos, debatidos. Mas para isso necessitamos conhecer, ter conhecimento do que são e de como utilizar as inovações científicas e tecnológicas, necessitamos ter uma posição crítica para tentar apontar soluções para os problemas sociais.

É inegável que hoje a Química se relaciona às grandes preocupações inerentes ao futuro da humanidade, como a questão energética, a poluição, os recursos naturais, a saúde. No entanto, as pessoas não sabem qual a relevância da Química para o bem-estar do ser humano.

Os conflitos são imensos e a escola enfrenta isso. São muitas as incertezas. São muitos os conhecimentos que emergem na sociedade, no entanto, o que se vê é que a educação se torna fragmentada, ou seja, temos uma expansão absurda de conhecimento, mas, trata-se de um conhecimento abordado de forma estanque, isolada, não relacionável. Os conhecimentos são desintegrados de nossas vidas, sem delas participar, resumem-se a serem usados por apenas alguns especialistas. Desse modo, precisamos dar importância à capacidade de contextualizar, de integrar, que devem ser consideradas como habilidades a serem construídas.

Logicamente não necessitamos de conhecimentos químicos tão especializados para viver em sociedade, mas é importante, pelo menos, que os indivíduos se enriqueçam culturalmente, que tenham conhecimentos básicos de Ciências e Química e tenham consciência e interpretem as suas interações em nossas vidas. Acreditamos que esse é um dos papéis a ser desempenhado pelo professor de Química, ou seja, trabalhar com seus alunos a construção de sua cidadania.

\section{CONSIDERANDO POSSIBILIDADES: EM DESTAQUE A FORMAÇÃO DOCENTE} no ensino de Química é a formação docente. São diversos os autores que se 
reportam a esse fato. Dessa forma, abordaremos a busca de possibilidades a partir desse viés.

Se nos voltarmos para a questão da formação docente, as licenciaturas em Química, à semelhança de outras apresentam, desde quando criadas, problemas quanto à sua estrutura curricular, eficácia e funcionalidade. Nas discussões que têm surgido entre os estudiosos que tentam reverter esse quadro, dois pontos se destacam: a inserção das questões sociais na educação e a reflexão crítica sobre as inter-relações entre Ciência-Tecnologia-Sociedade (AULER 2007, SANTOS E MORTIMER 2009, SANTOS E SCHNETZLER 2010)

No entanto, o que se tem observado, é que os licenciados saem de seus cursos com poucas condições de lidar com as situações de sala de aula, incluindo situações de ensino e aprendizagem que levem a uma aprendizagem significativa. Um quadro decorrente de sua formação inicial, que deixa lacunas, como se pode constatar nas pesquisas, principalmente no que concerne à dificuldade de adequar os conteúdos ao nível cognitivo dos alunos, à visão conteudista e neutra em relação à ciência, pouco conhecimento da dimensão pedagógica, o que inclui didática, planejamento, metodologias, avaliação e aspectos sociais, políticos, ideológicos, econômicos e culturais, dentre outras questões.

Nesse sentido, Schnetzler (2000), ao se referir, especificamente, ao ensino de Química reporta que a formação docente está distanciada da realidade da escola, principalmente a pública, levando as instituições formadoras a assumirem um modelo formativo acrítico. Severino (2001), por sua vez, afirma que a formação de professores neste modelo tradicional, separada da realidade cultural, social e política, torna o professor um simples repassador de conteúdos.

Uma formação docente com base no conhecimento fragmentado, linear e especializado e no professor como um executor de tarefas, não dá conta de uma formação docente capaz de formar cidadãos aptos a intervirem numa sociedade em transformação e regida por desigualdades sociais. Para Auler (2007), é necessário que haja uma compreensão crítica acerca das interações CTS para que ocorra uma leitura crítica da realidade, pois a dinâmica social contemporânea está fortemente impregnada pela Ciência e pela Tecnologia.

É reconhecido o papel da Ciência, em especial da Química, na formação do cidadão. Para Santos e Schnetzler (2010), nas propostas inovadoras de ensino de Química, nos últimos anos, é constatada a preocupação da vinculação do conhecimento químico com os aspectos sociais. Há, segundo os autores uma preocupação mundial com os fins da educação científica, o que tem levado a uns cem números de projetos em que se usa o ensino CTS. Ou seja, o ensino do conteúdo de Química no contexto autêntico do seu meio tecnológico e social. Uma preocupação deve ser a tomada de decisão, que tenha como base a inter-relação Ciência, Tecnologia e Sociedade, em uma concepção de Ciência como um processo social, histórico e não neutra.

Nesse panorama, é necessário que o professor seja capaz de despertar no aluno o senso crítico, fato possível através de uma reflexão constante da realidade social. Desse modo, a formação para a cidadania, como já enfatizamos, para que decisões possam ser tomadas, é fator importante na educação da atualidade, pois a preocupação com as questões sociais perante o desenvolvimento científico e tecnológico é uma premissa da sociedade, segundo Vilches et al, (2009), o que exige um mínimo de formação científica para uma reflexão crítica. 
Mas fica em dúvida a própria formação do formador, a nossa formação como formadores, no instante em que não tivemos essa formação, nossos currículos não contemplaram isso. Nós, como professores de Educação Superior não tivemos a oportunidade de englobar essas dimensões formativas. Então, como reverter isso merece reflexão.

Mudar as estruturas curriculares dos cursos de Licenciatura em Química, adicionando disciplinas, aumentando o estágio curricular dos futuros docentes, criando novos projetos curriculares, é insuficiente. Para que a formação do professor de Química seja embasada em perspectivas da contextualização e da interdisciplinaridade necessita considerar uma nova orientação curricular, enfocando aspectos sociais, políticos, econômicos, culturais, éticos e ambientais, visando criar um espaço de reflexão e de crítica.

Segundo Maués (2005), o processo de globalização por que passou a sociedade, trouxe mudanças econômicas sociais e políticas que atingiram as escolas e, consequentemente, a formação docente. No entanto, uma formação docente não pode ser construída, segundo Nóvoa (1997) por acumulação de cursos ou de técnicas. É necessário um trabalho que envolva reflexividade crítica sobre as práticas e de reconstrução permanente de sua identidade. Essa reflexão deve ser erigida no âmago de um contexto político, social e cultural em que o professor está inserido.

Uma formação de professores de Química transformadora requer que se alie teoria e prática, ação e reflexão. Todo o processo formativo deve embasar-se na reflexão tanto do formando, quanto do formador, com o saber docente se fundamentando na práxis (movimento de ação-reflexão-ação), rompendo modelos estagnados mecanicistas, procurando a autonomia e a emancipação, de acordo com Ghedin (2002).

Reflexões em grupo, que levem à análise da realidade e do cotidiano do professor, o estabelecimento de diálogos críticos, em idas e vindas, com vistas à reconceptualização, são ações fulcrais nesse processo, principalmente na formação inicial.

Por outro lado, é necessária a desmistificação da ideia de uma cultura curricular em que só os conhecimentos científicos são suficientes. Elementos de criticidade, de formação de habilidades, de atitudes, de procedimentos, aliados à atitude reflexiva são fundamentais.

Apesar dos esforços de mudanças, ainda vemos os cursos de Licenciatura preocupados somente com a transmissão de conteúdos, não há a preocupação com a preparação pedagógica, com a questão da contextualização, com a articulação de saberes disciplinares e pedagógicos, com a teoria e a prática entrelaçadas, de modo a possibilitar a relação com a realidade, com o cotidiano, com o contexto social e que vise à formação cidadã.

Não pode ser perdida de vista a necessidade de relacionar o conhecimento científico com outros, em uma perspectiva de ampliar saberes, na possibilidade de intervir na realidade social, de considerar questões econômicas, políticas, sociais, culturais e ideológicas, procurando a melhoria da sociedade e de seu bem-estar.

Uma formação docente nessa perspectiva social e científica necessita de mudanças posturais, tanto do professor, quanto do aluno. O conteúdo a ser trabalhado deverá ter em mente a inserção do aluno como um transformador 
social. Nesse sentido, deve ser um trabalho "caracterizado pela organização conceitual centrada em temas sociais, pelo desenvolvimento de atitudes de julgamento, por uma concepção de ciência voltada para o interesse social, visando compreender as implicações sociais do conhecimento científico" (SANTOS E SCHNETZLER, 2010, p.67).

Torna-se interessante ressaltar que, segundo Zabala (2014), a prática docente é influenciada por uma série de fatores, sendo considerada fluida e complexa, onde são expressos valores e ideias. Quanto a isso, segundo Freire (2013), a prática educativa é rica em cores políticas e ideológicas e que pode trazer no seu íntimo tanto intenções de estímulo à atitude crítica, quanto de submissão do aprendiz, possibilitando uma atitude de passividade. Desse modo, o professor deve estar atento à complexidade do ato educativo, de modo a perceber e compreender as atividades sociais que se desenrolam na escola, respeitando seus contextos e sua pluralidade.

Nesse processo, de reinvenção da prática docente tendo em vista uma perspectiva social na educação em Ciências - Química, não podemos deixar de considerar, tomando as ideias de Reigota (2014) como base, de que a Educação Ambiental é uma educação política, que busca formar um cidadão em sua essência, um cidadão que busca a liberdade, a autonomia e a intervenção. Ou seja

\footnotetext{
Educação Ambiental é a análise das relações políticas, econômicas, sociais e culturais entre a humanidade e a natureza e as relações entre humanos, visam à superação dos mecanismos de controle e de dominação que impedem a participação livre, consciente e democrática de todos. (REIGOTA, 2014, p. 13)
}

Dessa forma, a análise, a reflexão crítica e colaborativa parecem ser caminhos para que professores busquem novas práticas, de acordo com os contextos em que estão inseridos, que provoquem transformações no ensino e aprendizagem de Química e que permitam a formação para a cidadania. Uma concepção de formação docente a partir da reflexão de sua prática, desenvolvida em colaboração com seus pares, é promissora.

Por outro lado, as lacunas da formação inicial podem ser preenchidas por intermédio da formação continuada, o que demanda esforços de vários setores e não pode visar uma mudança superficial, com pequenas adaptações. Pelo contrário, essas mudanças devem ser mais profundas e duradouras. Planejamentos cooperativos também podem ser estratégias de mudanças na operacionalização dos currículos universitários. Acreditamos que ações coletivas no planejar, executar, acompanhar e avaliar são estratégias que podem ser utilizadas por grupos de professores e podem transcender a ação puramente disciplinar, permitindo uma organização interdisciplinar, fugindo da linearidade do conhecimento escolar, pois podem fazer vicejar novos espaços de pesquisa, de formação e de prática.

Para finalizar, alguns questionamentos podem ajudar para a nossa reflexão. Podemos nos perguntar: o que temos feito de concreto, nós, a escola e o próprio ensino de Química, para fornecer aos alunos os instrumentos necessários para o exercício da cidadania? Como podemos desenvolver conteúdos para que haja contribuição efetiva para a formação de cidadãos? De que modo podemos pensar e fundamentar de forma mais concreta o ensino de Química na procura de privilegiar a dimensão ambiental para favorecer a formação para a cidadania? 
Cientes de que essas são questões a serem refletidas, a nossa posição é de que acreditamos em uma formação docente que possibilite aos licenciandos se apropriar dos conteúdos escolares necessários para o desenvolvimento pessoal, profissional e a integração social. Os aspectos a serem enfatizados na aprendizagem das Ciências devem perpassar por uma formação crítico-reflexiva, analisando potencialidades, limitações e consequências da Ciência e Tecnologia em situações problemas da vida real. 


\title{
Aspects of the environmental dimension and chemical education: discussing possibilities
}

\begin{abstract}
Environmental education and the contextualization of teaching have had a recurrent approach in scientific works of several areas of knowledge today. In meetings, conferences and debates the theme has a relevant place, being the common point the search for a new social, ethical and moral mentality with regard to environmental issues. In this sense, scientific education, more specifically, chemical education plays a decisive role, being able not only to raise awareness but to strengthen the awareness of students and future professional citizens. However, the questions arise: do teacher education curricula, in the case of undergraduates, express this concern? Is this issue being addressed by teachers and other educational agents? And what about the training of trainers who will train the future teachers of Basic Education? In this article we are going to focus on these issues, which encompass legal determinations, real situations, training needs and perspectives for a citizen training. It is, in fact, some reflections based on works that encompass the subject, with a view to intensify the debate on the subject, to discuss a subject that is on the agenda and is being discussed frequently.
\end{abstract}

KEYWORDS: Environmental dimension. Chemical education. Citizen legislation and training. 


\section{REFERÊNCIAS}

AMARAL, I. A. do. Educação Ambiental e o ensino de Ciências: uma história de controvérsias. In: Revista Pro-posições. V. 12. N.1 (34), março de 2001, p. 73-93.

AULER, D. Enfoque ciência-tecnologia-sociedade: pressupostos para o contexto brasileiro. In: Ciência e Ensino, Piracicaba, vol. 1, número especial, 20p. Nov. 2007.

BRASIL. Lei de Diretrizes e Bases da Educação Nacional. Lei número 9394, 20 de dezembro de 1996.

BRASIL. Ministério da Educação. Orientações Curriculares para o Ensino Médio. v.2. Ciências da Natureza, Matemática e suas tecnologias. Brasília. SEB, 2006.

Conselho Nacional de Educação (CNE). Resolução n. 3, de 26 de junho de 1998. Institui as Diretrizes Curriculares Nacionais para o Ensino Médio. Diário Oficial da República Federativa do Brasil, Brasília, DF, 5 ago. 1998.

Ministério da Educação. Diretrizes Curriculares Nacionais para os Cursos de Química. Brasília, DF: CNE, 2001.

CACHAPUZ, A. F., Do ensino das ciências: seis ideias que aprendi. In: PESSOA DE CARVALHO, A. M.; CACHAPUZ, A. F. e GIL-ÉREZ, D. (Orgs.) O ensino das ciências como compromisso social: os caminhos que percorremos. São Paulo: Cortez, 2012.

FREIRE, Paulo. Pedagogia da autonomia, saberes necessários à prática educativa. São Paulo: Paz e terra, 2013.

GATTI, B. A. Formação de Professores e Carreira: Problemas e Movimento de Renovação. Campinas, SP: Autores Associados, 2000, 119p.

GHEDIN, E. Professor reflexivo: da alienação da técnica à autonomia da crítica. In: PIMENTA, S.. G.; GHEDIN, E. (Orgs.). Professor reflexivo no Brasil, gênese e crítica de um conceito. São Paulo: Cortez, 2002, Cap. 6, p.129-150.

GOBARA, S. T. ET AL. O ensino de ciências sob o enfoque da educação ambiental. Cad. Cat. Ens. Fís. Florianópolis, v. 9, n. 2: p. 171-182, ago., 1992. 
LOPES, A. C. Os Parâmetros Curriculares Nacionais para o Ensino Médio e a submissão ao mundo produtivo: o caso do conceito de contextualização. In: Educação \& Sociedade. Campinas. v.23, n.80. 2002, p.386-400.

MACHADO, A. H. \& MORTIMER, E. F. Química para o ensino médio: fundamentos, pressupostos e o fazer cotidiano. In: ZANON, L. B. \& MALDANER, O. A. (Orgs.). Fundamentos e Propostas de ensino de Química para a educação básica no Brasil. ljuí: Ed. Ijuí, 2007.

MAKNAMARA, M. Educação ambiental e ensino de ciências em escolas públicas alagoanas. Contraponto, v. 9, n.1, p. 55-64, 2009.

MALDANER, O. A. Concepções epistemológicas no ensino de ciências. In: SCHNETZLER, R. P. e ARAGÃO, M. R. de. Ensino de ciências: fundamentos e abordagens. Campinas: R. Vieira Gráfica e Editora Ltda, 2000.

MAUÉS, O. C. As Políticas de Formação de Professores: A “Universitarização" e a Prática. In: MAUÉS, Olgaíses \& LIMA, Ronaldo (Orgs.). A Lógica das Competências na Formação Docente. Belém - PA: Edufpa, 2005.

NÓVOA, A. Formação de professores e formação docente. In: NÓVOA, A. (Org.). Os professores e a sua formação. Lisboa: Dom Quixote, 1997, p. 9-14.

PEREIRA, J. E. D.. A Formação de Professores nas Licenciaturas: Velhos Problemas, Novas Questões. In: Encontro Nacional de Didática e Prática de Ensino, 9, 1998. Águas de Lindóia, SP: 1998, p. 341-357.

REIGOTA, M. Meio ambiente e representação social. São Paulo: Cortez, 2010. O que é educação ambiental. São Paulo: Brasiliense, 2014.

RIBEIRO, J. A. G.; CAVASSAN, O. Um olhar epistemológico sobre o vocábulo ambiente: algumas contribuições para pensarmos a ecologia e a educação ambiental. In: Filosofia e História da Biologia, v. 7, n. 2, p. 241-261, 2012.

SANTOS, W. L. P. dos at all. Química e sociedade: ensinando química pela construção contextualizada dos conceitos químicos. In: ZANON, L. B. \& MALDANER, O. A. (Orgs.). Fundamentos e propostas de ensino de química para a educação básica no Brasil. Ijuí: Ed. Ijuí, 2007. 
SANTOS, W. L. P. dos; MORTIMER, E. F. Abordagem de Aspectos Sociocientíficos em Aulas de Ciências: Possibilidades e Limitações. Revista Investigações em Ensino de Ciências, Porto Alegre-RS, v. 14(2), p. 191-218, 2009. Disponível em: <http://www.if.ufrgs.br/ienci/artigos/Artigo_ID214/v14_n2_a2009.pdf > Acesso em: 12 Out. 2011.

SEVERINO, A. J. Educação, Sujeito e História. São Paulo: Olho d'água, 2001, 171p.

SHNETZLER, R. P. O professor de ciências: problemas e tendências de sua formação. In: SCHNETZLER, R. P.; ARAGÃO, R. M. R. de (Orgs). Ensino de ciências: fundamentos e abordagens. Piracicaba, SP: Capes/Unimep, 2000, Cap. 1, p. 1241.

VILCHES, A.; MARQUES, L.; GIL-PÉREZ, D. e PRAIA, J. Da Necessidade de uma Formação Científica para uma Educação para a Cidadania. In: I Simpósio de Pesquisa em Ensino e História de Ciências da Terra e III Simpósio Nacional sobre Ensino de Geologia no Brasil, 2009. Campinas-SP: 2009, p. 421-426, CD ROOM.

ZABALA, A. A prática educativa: como ensinar. Porto Alegre: Artmed, 2014.
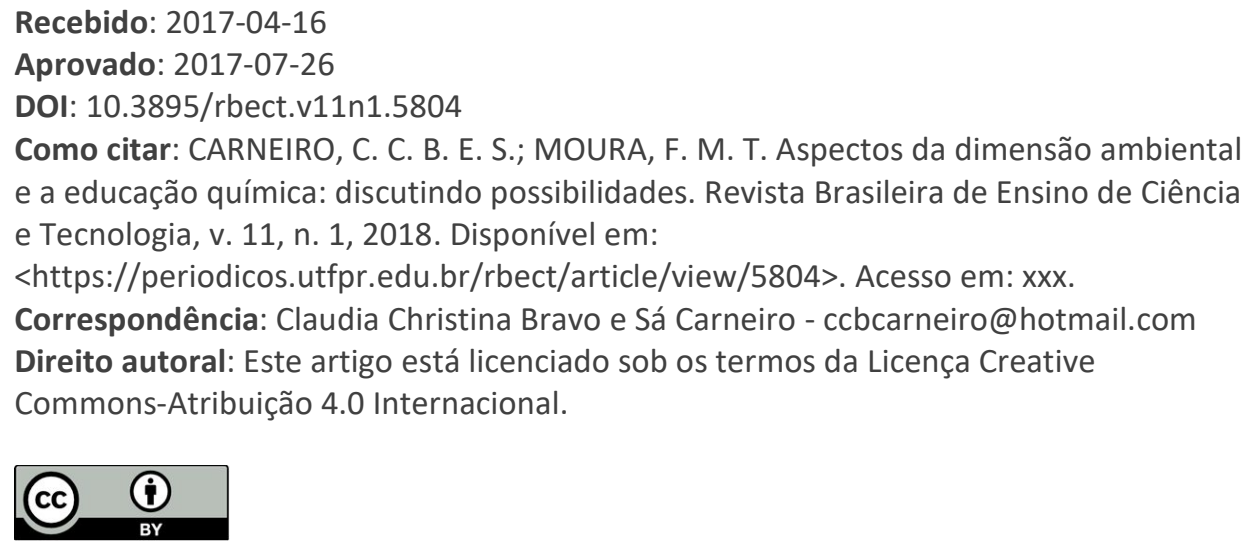